\title{
Robotic Therapies for Children with Cerebral Palsy: A Systematic Review
}

\section{Cristina Bayon ${ }^{1}$, Rafael Raya ${ }^{2}$, Sergio Lerma Lara ${ }^{3}$, Oscar Ramirez ${ }^{1}$, Ignacio Serrano $J^{1}$ and Eduardo Rocon ${ }^{1,4}$}

${ }^{1}$ Center of Robotics and Automation, Consejo Superior de Investigaciones Científicas, 28500, Arganda del Rey, Spain

Universidad San Pablo CEU, Madrid, Spain

${ }^{3}$ Gait analysis laboratory, Hospital Infantil Universitario Nino Jesus, 28009, Madrid, Spain

${ }^{4}$ Post-graduate Program, Universidade Federal do Espirito Santo, 29075-910, Vitoria, Brazil

Corresponding author: Cristina Bayon, Neural and Cognitive Engineering group, CAR, UPM-CSIC Ctra. Campo Real, km 0.200, La PovedaArganda del Rey, 28500 Madrid Spain. Tel: 0034 645743724; E-mail: cristina.bayon@csic.es

Received: Jan 19, 2016; Accepted: Feb 02, 2016; Published: Feb 10, 2016

Citation: Bayon C, Raya R, Lerma Lara S, et al. Robotic Therapies for Children with Cerebral Palsy: a Systematic Review. Transl Biomed. 2016, 7: 1.

\section{Abstract}

Title: This paper presents a systematic review of robotic devices and therapies for cerebral palsy (CP), trying to shed some light on the present literature on robot-based $\mathrm{CP}$ rehabilitation.

Background: Recent publications have demonstrated that robot-assisted therapies may constitute an effective tool for the compensation and rehabilitation of the functional skills of people with CP. The most important robotic devices for lower and upper limb rehabilitation were selected, specifying the assisted therapies, experiments done with them, and their results in children with CP.

Methods: Scientific articles were obtained by means of an extensive search in electronic databases, primarily PubMed and Scopus. Papers published from the year 2000 to 2015 were considered for inclusion. The search was performed by using the following keywords in combination: robot, Cerebral Palsy, children, and therapies. Moreover, some web pages about CP organizations were used to complete the review.

Conclusions: There is still a lack of randomized clinical trials with a representative number of subjects, which makes it difficult to evaluate the impact of robot-based therapy, especially the long-term effects. The inclusion of cognitive aspects into the therapies and the design of virtual scenarios in combination with robotic devices provide promising results.

Keywords: Cerebral Palsy; Robotic Therapy; Rehabilitation; Review

\section{Introduction}

Cerebral palsy (CP) is one of the most common disabilities in childhood and makes heavy demands on families, children, and health, educational, and social services. The most frequently cited definitions of $\mathrm{CP}$ are: a disorder of posture and movement due to a defect or lesion in the immature brain [1] or a group of movement and posture disorders that are associated with progressive alteration of the immature brain during fetal or infant growth. The disorders are permanent but not invariable, and these disorders do place some limitations on daily living. CP is often associated with sensory deficits, cognition impairments, communication and motor disabilities, behavior issues, seizure disorder, pain, and secondary musculoskeletal problems [1]. The main causes and risk factors of $C P$ are: multiple birth, extreme prematurity, birth asphyxia, feeding issues, prolonged hospitalization, or postnatal infection; this disorder is more common in males [2].

Individuals with CP are normally categorized into classes or groups, though most people with $\mathrm{CP}$ have a combination or two or more types [3]. From a topographic point of view, depending on how many structures are involved, people with $\mathrm{CP}$ could be classified as having Hemiplegia, Paraplegia, Tetraplegia, Diplegia, or Monoplegia. This classification, used in combination with the type of movement disorder (Spasticity, Dyskinesia, Ataxia, or Mixed), offers an interesting approach for clinical practice. Functional classification procedures are recommended when a clinical decision is required. The gross motor function classification system (GMFCS) [4] and the functional mobility scale (FMS) are the most commonly used scales [5]. GMFCS defines five levels of $\mathrm{CP}$ depend on functional limitations, the need for hand-held mobility devices (such as walkers, crutches or canes) or wheeled mobility, and to a much lesser extent, quality of movement. This bibliography also recognizes that the levels of GMFCS are based on age (groups under two years old, between two and four years old, between four and six years old, between six and 12 years old and between 12 and 18 years old). 
A cure for $\mathrm{CP}$, which means repair of the underlying brain damage, is not currently available; therefore, the management of children with CP usually focuses on maintaining and improving quality of life and function and preventing secondary complications. Patients with $\mathrm{CP}$ are at a high risk of developing musculoskeletal problems that are mainly related to physical growth, abnormal muscle tone, weakness, a lack of mobility, poor balance, and a loss of selective motor control. Treatments for CP patients depend on the specific patient's pathology and range from physical therapy to medication and surgery. When distinguishing therapeutic approaches by their main emphasis, the following basic principles can be recognized [6]: 1) emphasis on normalization of the quality of movement and 2) emphasis on functional activities, which focuses on the development of skills necessary for the performance of activities of daily living. These activities include playing, self-care activities, such as dressing, grooming, and feeding, and fine motor tasks, such as writing and drawing. Children treated with an emphasis on functional activities have better clinical results than treatments that focus on movement [7]. The aim of the rehabilitation is to improve the patient's independence in daily life activities [8]; it is during the early stages of development that fundamental abilities and skills are developed [9] and therefore it is essential to give infants with $\mathrm{CP}$ an opportunity to interact with the environment for integral development (physical and cognitive). The success rate of rehabilitation increases in accordance with the intensity of therapy, repetition, and the patient's motivation, especially in children [8].

$\mathrm{CP}$ is the most common physical disability affecting the functional development of children. In the United States alone, 500,000 infants are affected by CP $[10,11]$; in Europe, these figures are even higher [12]. Medical costs were markedly higher for children with $\mathrm{CP}$ and the costs were highest for children with both CP and intellectual disability [13].

Medical costs for children with $\mathrm{CP}$ alone were 10 times higher than for children without CP or intellectual disability (\$16,721 vs. $\$ 1,674$ in 2005 dollars).

Medical costs for children with both $\mathrm{CP}$ and intellectual disability were 26 times higher than for children without CP or intellectual disability (\$43,338 vs. $\$ 1,674$ in 2005 dollars).

The estimated lifetime cost to care for an individual with CP is nearly $\$ 1$ million. The combined estimated lifetime costs for all people with CP who were born in 2000 will total \$11.5 billion in direct and indirect costs [13].

The main therapies focused on the rehabilitation of people with $\mathrm{CP}$ are: 1) physical and occupational therapy, which is focused in walking, standing, stretching exercises, and flexibility; 2) oral medication, which is generalized to spasticity treatment; 3) orthotics, which are normally used in children with $\mathrm{CP}$ to try to prevent deformities, contractures, and pain; 4) Botulinum toxin to treat localized spasticity; 5) ferule and plaster to avoid moderate contractures; 6) multilevel orthopedic surgery, which implies that there are at least two surgical orthopedic procedures (soft tissue and/or bones) at different anatomic points and in both lower limbs in only one surgery process, [14]; 7) neurosurgical procedures; 8) partial bodyweight-supported treadmill training (PBWSTT) and constraint-induced movement therapy (CIMT), which are based on motor learning theories and promote the standardization of gait pattern by involving sensory information and reflection components of gait; and 9) robotaided gait therapy (RAGT), which may be an effective tool to compensate and/or rehabilitate the functional skills of people with CP [15].

New strategies are needed to help promote, maintain, and rehabilitate functional capacity and thereby diminish the dedication and assistance required and the economic demands that this condition represents for the patient, caregivers, and society [16]. Robot-assisted therapies appear to be alternative and complementary treatments [8]. In light of this, this paper presents a critical review of the robot-assisted therapies specifically designed for people with $\mathrm{CP}$, focusing on locomotion (lower limb) and manipulation (upper limb).

\section{Methods}

This systematic review is according to the principles of the preferred reporting items for systematic reviews and metaanalyses (PRISMA) guidelines. This study did not require human participation.

Scientific articles were obtained by means of an extensive search in electronic databases, primarily PubMed and Scopus. Papers published between 2000 and 2015 were considered for inclusion. Although a few references published before the year 2000 were selected, the more important articles in this review were released in the last 15 years. The search was performed by using the following keywords in combination: robot, cerebral palsy, children, and therapies. The papers were preselected by reading the titles and abstracts. The selection was completed after reading the full text. Moreover, some web pages about $\mathrm{CP}$ organizations were used to complete the information for this review.

\section{Results}

A total of 226 articles were identified once we deleted duplicates. Of these, 73 were excluded because they were too old (papers without relevance published before 2000) and 28 others were removed because they did not address CP. After reading the full texts, we excluded 81 assessed articles because they didn't adapt to our final inclusion terms, which were discussed by the heterogeneous group of authors (including engineers, medical staff and physiotherapists). The result of this was a total of 44 reviewed studies. They were divided in this way: 22 for robot-assisted rehabilitation for the lower limb; 9 included in robot-assisted rehabilitation for the upper limb; 7 in terms of virtual reality (VR) in collaboration with robotic rehabilitation in $\mathrm{CP}$; and 6 in the context of translating the experiments to clinical scenarios. The flow of studies and reasons for exclusion are summarized in the PRISMA diagram (Figure 1). 


\section{Gait: robot-assisted rehabilitation for the lower}

\section{limbs}

One of the main goals of neuromotor rehabilitation is the recovery of locomotion ability because it allows patients to improve their independence and quality of life. Traditionally, physical therapy plays a critical role in lower limb rehabilitation. Treadmill training, usually PBWSTT, is also gaining importance because the therapy is provided in a controlled and safe way. Generally, training protocols include a gradual increase of difficulty level by decreasing the amount of body weight support provided, increasing the treadmill speed, or increasing the time spent walking. In this framework, robotics is emerging as a leading technology for the motor rehabilitation of subjects with neurological impairments and, in particular, the recovery of walking. In fact, RAGT has some promising advantages over traditional training or PBWSTT in that it is intensive, controlled, repetitive, and provided with goal-oriented tasks, which is known to be related to cortical organization and motor learning processes [17]. This aspect is particularly important for the pediatric population, who could obtain better results thanks to their higher neuroplasticity.

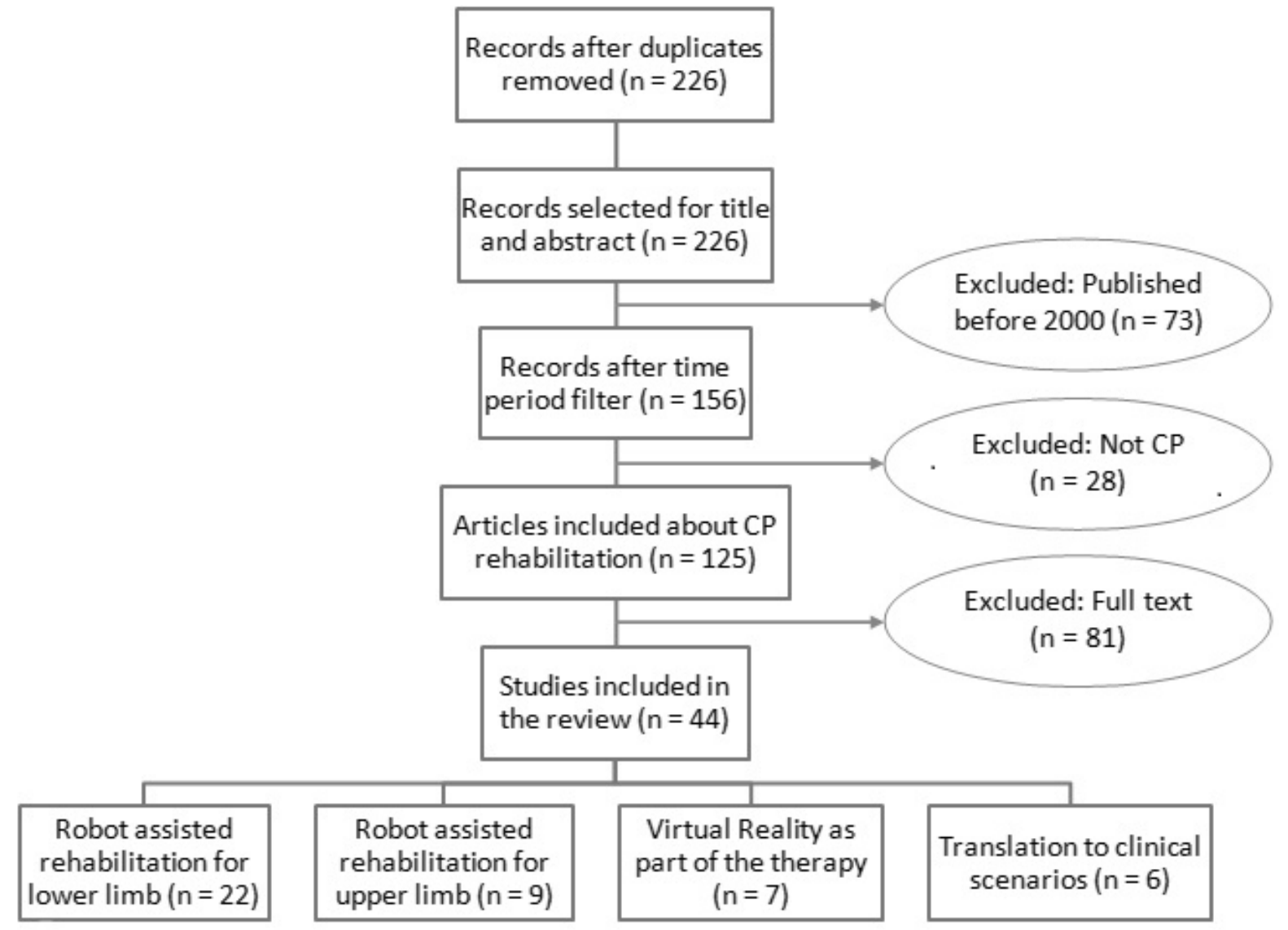

Figure 1 PRISMA flow diagram

There are basically two groups of assistive robotic devices to help people with mobility problems: alternative devices and empowering (or augmentative) ones. These solutions are selected based on the degree of the user's disability. In the case of total incapacity of mobility (including both bipedestation and locomotion), alternative solutions are used, such as wheelchairs or special vehicles. People who have reduced mobility commonly use augmentative devices that use their residual capabilities, e.g., walkers and exoskeleton robots are augmentative devices that assist in standing, balance, and locomotion [18].

Walkers are intended to help users' navigation. Smart Walkers are robotic devices based on walkers that are optimized to improve the human-machine interaction and, as a result, improve the acceptance and functionality of these systems in rehabilitation. As walkers take advantage of the user's remaining locomotion capability, they also help to avoid the early and deteriorative use of alternative devices, most commonly wheelchairs.

Exoskeleton Robots are mechatronic devices whose segments and joints correspond to some extent to those of the human body and the system is externally coupled to the person. In rehabilitation applications, exoskeletons should be able to replicate, with a patient, the movements performed with a therapist during the treatment. In the case of functional compensation, exoskeletons are designed to support the execution of activities of daily living by assisting the user in the basic motor functions. The exoskeletons were intended to provide either joint support by means of brakes or clutches [19-22] or actively add power to the joints, thus providing a 
means to control and complete joint movements [23-26]. In addition, the sensors attached to the exoskeleton can assess the patient's forces and movements, which would give the therapist quantitative feedback regarding the patient's recovery and rehabilitation process. Therefore, the exoskeleton could act as a tool for the measurement of the performance and evolution of the treatment [27].

A commercially available device that illustrates the use of robotics for the assistance of people with CP is the NF-Walker (Figure 2), a hybrid assistive device that gives dynamic support to standing position and gait. The user's weight is discharged by the device's wheels [28]. This device provides motor stimulation for users and gives them a sense of accomplishment. It can be individually adapted to the user, who is supported in an upright and corrected position with both hands free. The NF-Walker was developed by Made for Movement. To evaluate the applicability of this robotic walking aid in non-ambulatory children with CP, Smania et al. [29] conducted an experiment with an 11-year-old boy (GMFCS IV) that was unable to walk independently due to spastic tetraparesis. The outcomes measures were: 2-minute walking test, 10-meter walking test, respiratory and heart parameters, and energy cost of locomotion. The results were satisfactory in most of the tests, suggesting that the NF-Walker may allow children suffering from $\mathrm{CP}$ with severe gait impairment to move around in their environment. This device may potentially stimulate the development of gait in children with neurological gait impairment.

The other devices developed by Made for Movement are Innowalk and Innowalk-Pro. Both Innowalk and Innowalk-Pro are robots intended for rehabilitation programs that can induce healthy gait patterns in their users [30]. Innowalk gives disabled people the opportunity to experience assisted, guided, and repetitive movement, which is very beneficial for rehabilitation after surgery, and provides steady and corrected leg movement in sitting and/or standing positions [31]. With the Innowalk-Pro, the upper limbs, lower limbs and InnowalkPro movements are coordinated as part of the therapy [32] The Innowalk and Innowalk-Pro are static devices because the patient doesn't move through the room. In [33], five children with GMFCS scores between III and V were chosen for an experiment where they had to use the Innowalk for 4 weeks ( 5 times per week, 30 minutes per day). At the end of the study, four of five children had increased muscle mass, three of five improved their joint deflection, and all of them improved their posture control. Moreover, $72.2 \%$ of patients' caregivers stated that the child enjoyed using Innowalk, while $85.1 \%$ stated that Innowalk helped to maintain the child's function [31].

Lokomat (Figure $\mathbf{3}$ ) is a robotic platform designed by Hocoma AG for the treatment of RAGT in adults and children and is the most widely used hospital rehabilitation robotic platform worldwide. Pediatric Lokomat is adapted to the individual patient's anatomy. Its concept is similar to the Innowalk in that it practices rehabilitation therapies using repetitive movements. The Lokomat consists of a 2-leg exoskeleton with motor drives, a body weight support, and a synchronized treadmill. A study developed with 16 users that had previous strokes demonstrated that after treatment all patients had improved gait performance and motor function; although five patients were initially unable to walk in the Lokomat for 30 minutes, they succeeded in doing so within 1 to 3 days [34]. In another study that included CP patients, 33 patients (all GMFCS III initially) underwent 40 Lokomat sessions (nine females and 24 males, all around 7 years of age); after 40 sessions of 20 minutes each, eight users (24\%) could walk without assistance and achieved GMFCS II, and $15.3 \%$ of the remaining patients showed improvements in their gait pattern [35].

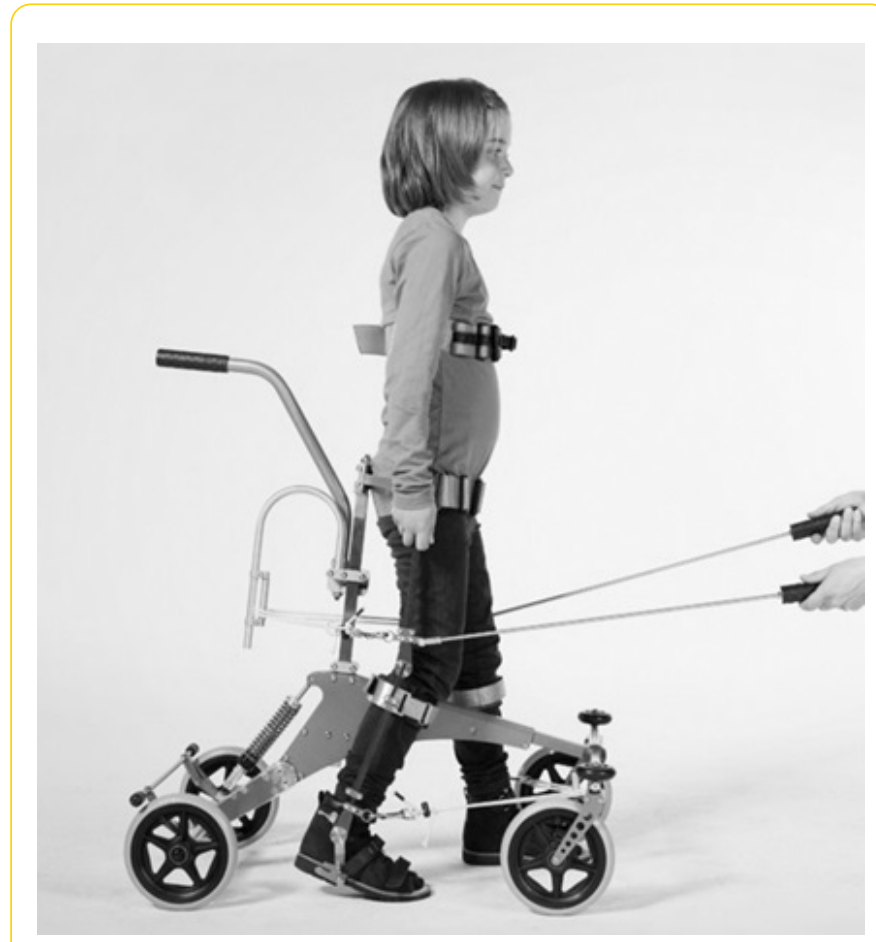

Figure 2 NF-Walker. Reprinted from [28]

Borggraefe et al. [36] showed positive effects after 12 training sessions with the Lokomat and described improvements in standing and walking ability (dimensions $D$ and $\mathrm{E}$ of the GMFM, respectively) in 20 children with bilateral $\mathrm{CP}$, which were maintained after a period of six months. The authors also reported the intervention's efficacy was dosedependent, as the improvements in the task (walking) measured in dimension $\mathrm{E}$ of the GMFM were positively correlated with higher distance and time walked.

Another system for robotic-assisted gait training available in the market for the rehabilitation of children with $\mathrm{CP}$ is the Gait Trainer GT-1 RehaStim (Figure 4), which aims to improve the patient's ability to walk through repetitive training. The weight of the user is relieved and children are positioned on two footplates that simulate the stance and swing phases of gait [37]. A recent study checked the effectiveness of this device, compared to conventional training, in 18 children with diplegia or tetraplegia. The GT-1 group received 30 minutes of robot training plus 10 minutes of stretching exercises, while the control group received 40 minutes of conventional physiotherapy; all the subjects underwent 10 sessions over a 
2-week period. The results were satisfactory for the experimental group, showing improvements on the 10-meter walk test, 6-minute walk test, hip kinematics, speed, and step length, which was maintained 1 month after the treatment had finished [37].

In a nutshell, Table 1 summarizes the most relevant robotic platforms found in the literature.

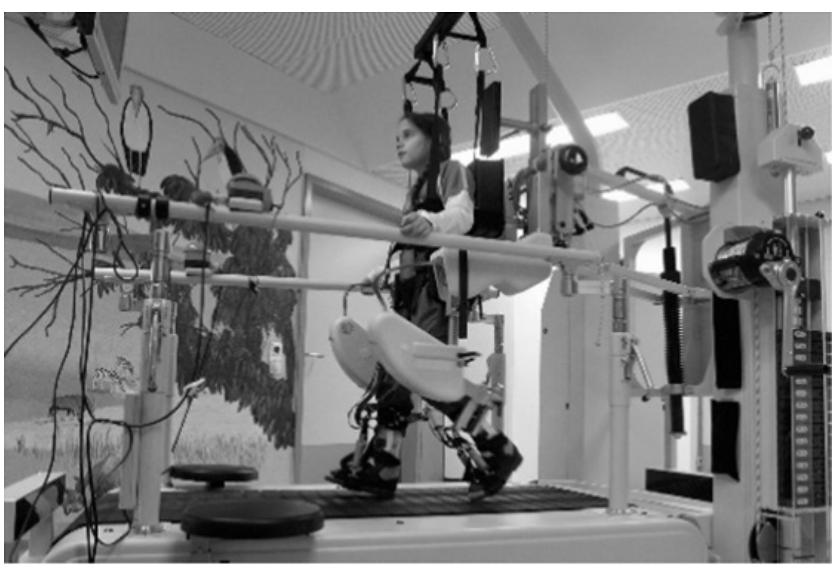

Figure 3 Lokomat. Reprinted from [17]

\section{Manipulation: robot-assisted rehabilitation for the upper limbs}

There are currently a limited number of robotic systems targeting the upper extremity that have been applied to children with CP [38]. These devices work via goal-directed tasks and reaching movements to rehabilitate hand and arm function.

The InMotion2, also called the shoulder-elbow robot, is an end-effector robot, a commercial version of MIT-MANUS (Interactive Motion Technologies) [39], which is capable of continuously adapting to and challenging each patient's ability. This device aims to improve the patient's range of motion, coordination, strength, movement speed, and smoothness. One hundred and seventeen subjects that had previous strokes were trained with InMotion2, and during the training patients were able to execute shoulder and elbow joint movements with significantly greater independence. At the end of the experiment, the subjects were better able to draw circles [40]. In most cases, studies conducted with stroke patients have encouraged new experiments with people with $C P$, as in another experiment where 12 children aged 5-12 years with $\mathrm{CP}$ and upper-limb hemiplegia received robotic therapy twice a week for 8 weeks. The children showed significant improvement in their total quality of upper extremity skills test (QUEST) and Fugl-Meyer Assessment scores [39]. Following the distal approach, Interactive Motion Technologies developed the MIT-Manus InMotion3, which works with flexion, extension, pronation, and supination of the affected wrist. The results are similar to those of InMotion2, but in this case, InMotion3 can operate both as a standalone device and as an
InMotion2 module; InMotion3 has not yet been used in studies that include children with CP.

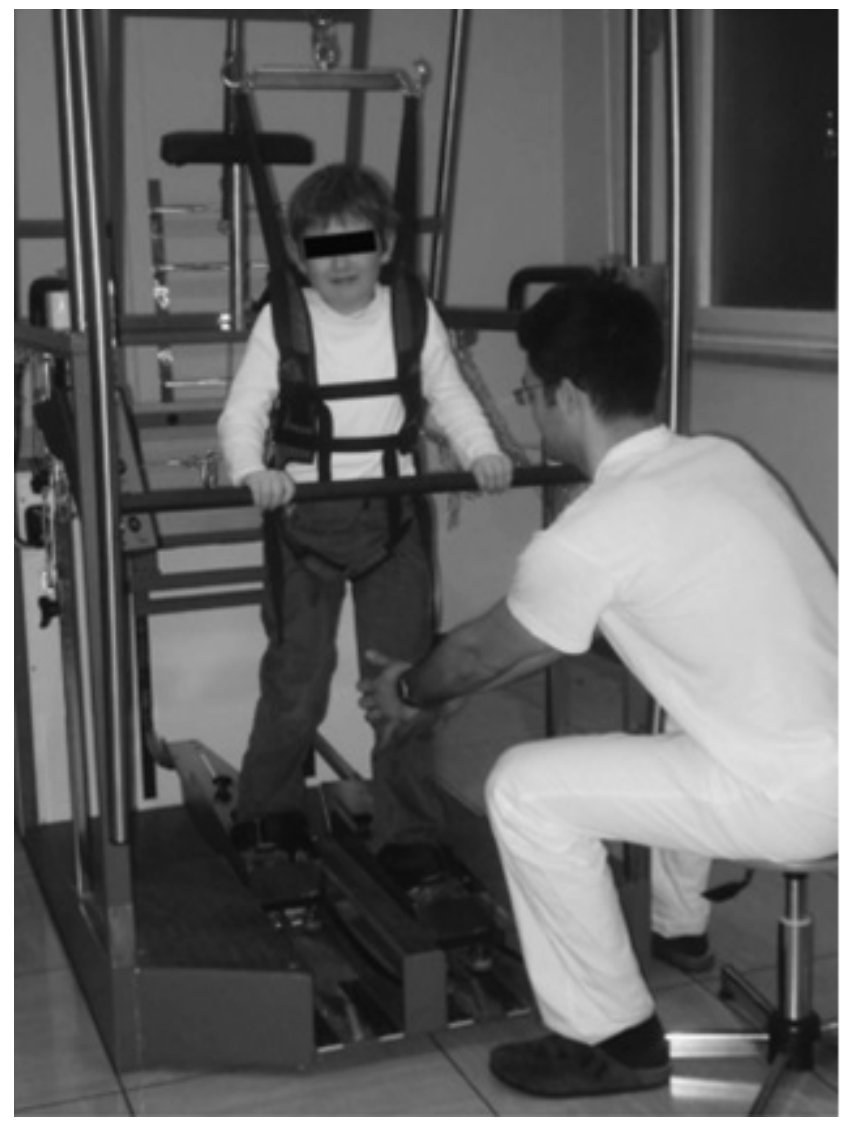

Figure 4 Training with GT-1. Reprinted from [37]

Another robotic system for the upper limbs is the New Jersey Institute of Technology's Robot-Assisted Virtual Rehabilitation System. It is comprised of a HapicMaster and a custom-made ring gimbal. This system has 6 degrees of freedom and is a force-controlled haptic interface [8]; it provides the user with a realistic haptic sensation and the power to closely simulate the weight and force found in a wide variety of human tasks. The programmable robot arm utilizes the admittance control (force control) paradigm, giving the device unique haptic specifications, and was used in combination with virtual scenarios to improve shoulder and elbow movements [41]. In a study that tested nine patients with $C P$, who performed nine 60 -minute sessions of 3 timed upper extremity tasks and several measurements of reaching kinematics, the patients improved in measures of motor activity in the Melbourne Assessment (MA) after treatment [8].

The ARMEO (Hocoma AG) system (based on the T-WREX system) proposes a rehabilitative exercise that allows early rehabilitation of motor abilities and provides adaptive arm support in a 3D workspace (Figure 5). The ARMEO system is focused on patients that lack sufficient strength to move their arm and hand against gravity [42]. Some springs can support the weight of the upper and lower arm [8], and the system can 
be adapted for each child. Unfortunately, no clinical trials have been performed with this system and people with CP.
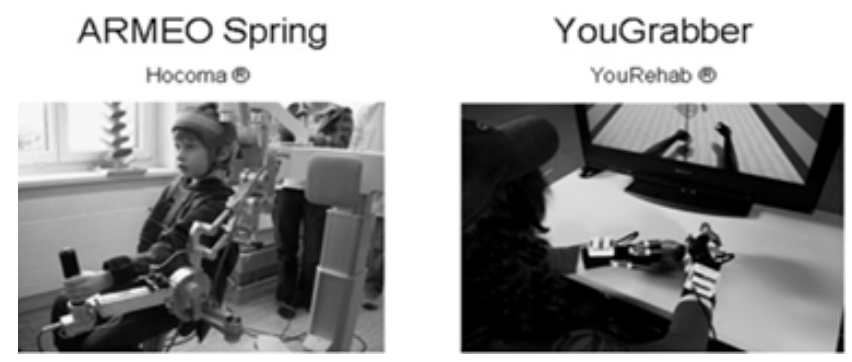

Figure 5 Armeo and YouGrabber. Reprinted from [8]

The YouGrabber System (Figure 5), developed by YouRehab Company, is a virtual rehabilitation system based on video games that uses a pair of data gloves and an infrared camera to capture the fingers' flexion. This system allows mirror movement training, and a particular advantage of YouGrabber is its ability to provide both unilateral and bilateral training [43]. The games are based on reach, grip, and transport tasks [8]. In the first study, five children with motor deficits in the upper limbs were tested with YouGrabber. The experiment was developed in nine sessions of 45 minutes each, and the task involved hand grasping and releasing, wrist pronation and supination, and arm reaching. The results were satisfactory: four out of five patients showed improvements in all measures in the MA [44].

Gilliaux et al. [45] assessed another robot-assisted therapy (REAPlan) through a single-blind randomized trial. Sixteen children with CP were randomized into two groups: a control group of eight users conducting five conventional therapy sessions per week over 8 weeks and a robotic group of eight users conducting three conventional therapy sessions and two robot-assisted sessions per week over 8 weeks. The REAPlan is a distal effector robot that allows for displacements of the upper limb in the horizontal plane. Outcome measures, such as QUEST and PEDI (Pediatric Evaluation of Disability Inventory), were analyzed. According to the authors, there was evidence that the robotic therapy was effective since the outcome measures improved significantly more in the robotic group than in the control group; is the authors also suggested studying the long-term effects of the therapy.

The classification of the most used devices for $\mathrm{CP}$ and the upper limbs is shown in Table 2.

\section{Discussion}

Robot-assisted therapy is a form of physical therapy that uses a robotic device to help a person with impaired functional ability to recover their function [46]. The cost and accessibility (not to mention boredom) of therapy in clinics generally reduces therapy compliance. The robotic device usually proposes a goal-directed task, which encourages the patient. This approach has interesting advantages compared to traditional therapy, because robotic therapy integrates functional tasks with accurate and assembled movements instead of repetitive movements without goals; as a result, the number of sessions, frequency, intensity, and finally the positive impact of the treatment are all typically increased. Additionally, these devices usually integrate assessment systems to objectively measure the progress of the therapy.

According to the results, numerous devices for the rehabilitation of gait in CP can be found [29,33,35-37]. Robotic exoskeletons to support human gait have become very popular because they propose interesting strategies to increase the frequency and intensity of the sessions. Some of the devices, which were designed for spinal cord injury or stroke patients, were recently adapted for people with CP. Most studies suggest that children with $\mathrm{CP}$ benefit from robotic-assisted gait therapy; however, since there is no standardization about the outcome measures used, it is difficult to describe and quantify those benefits precisely. Additionally, a more detailed description of the user's profile is required, especially in the case of users with $\mathrm{CP}$, whose motor particularities are very heterogeneous.

On the other hand, robot systems for the rehabilitation of the upper limbs are scarce, particularly for the rehabilitation of hand control; however, some studies demonstrate that robotic therapy can provide new opportunities for improving upper limb coordination $[8,39,44,45]$. Generally, the lack of longitudinal and randomized clinical trials for these robotic systems makes it difficult to evaluate the impact of the therapy after robotic training. Nevertheless, these rigorous studies are needed to understand the key ingredients underlying motor recovery. In spite of these outcomes, an optimal robotic training indication to the physiotherapist does not exist. Additionally, there are obstacles to the widespread adoption of robotic rehabilitation, including high economic costs and poor portability [47].

To improve current robotic therapies, novel concepts are emerging, such as VR, which brings cognitive aspects into the treatment and provides promising results [8].

\section{Virtual reality as part of robot-based therapy}

Recent studies have demonstrated that robot-assisted therapy, in combination with new rehabilitation techniques, motivates the patient (which is very important in the case of children) and improves the treatment. A new and advanced method of feedback is the application of virtual scenarios, where the user can interact with a virtual object in real time and feels that he or she is part of a virtual environment during the therapy [8]. Changes in cortical maps are driven by specific aspects of behavioral demand (i.e., motivation, skill acquisition) and are not simply the result of repetitive use or strength training [48].

VR is a very attractive tool to enable the adoption of biofeedback techniques for the treatment of children with $\mathrm{CP}$. In this scenario, biofeedback can be defined as the use of sensory feedback through which objective performance observation related to a specific motor task is presented to provide the child with immediate, consistent feedback of their 
performance [49]. The aim of providing patients with biofeedback during exercise is twofold: first, to improve the effectiveness of the rehabilitation treatment, both by allowing patients to adjust their movements according to the feedback of performance and by providing an incentive to exercise; and second, recording the physiological parameters to be fed back to the patient provides quantitative monitoring and documentation of the patient's progress during treatment. The latter feature is particularly important when the rehabilitation treatment is extensive and prolonged, which is typically the case with patients with $\mathrm{CP}$.

Table 1 The most relevant robotic platforms for lower limbs in CP

\begin{tabular}{|c|c|c|c|}
\hline Device & $\begin{array}{l}\text { Number of } \\
\text { patients }\end{array}$ & Therapies and measurements & Results \\
\hline \multirow{4}{*}{ NF-Walker [29] } & \multirow{4}{*}{1} & 2' walking test & \multirow{4}{*}{$\begin{array}{l}\text { Improvements in all tests. Use of NF-Walker may help children } \\
\text { with severe impairment of gait as a result of CP. }\end{array}$} \\
\hline & & $10 \mathrm{~m}$ walking test & \\
\hline & & Respiratory and heart parameters & \\
\hline & & Energy cost of locomotion & \\
\hline Innowalk [33] & 5 & $\begin{array}{l}\text { Session training with Innowalk: } 30 \mathrm{~min} / \text { day; } \\
5 \text { days/week; } 4 \text { weeks }\end{array}$ & $\begin{array}{l}4 \text { of } 5 \text { children increased muscle mass, } 3 \text { of } 5 \text { improved their } \\
\text { joint deflection, and all of them improved their posture control. }\end{array}$ \\
\hline Innowalk-Pro & - & - & Hasn't found any experiments with $\mathrm{CP}$ \\
\hline Lokomat $[35,36]$ & 33 & $\begin{array}{l}40 \text { sessions of } 20 \text { minutes each one } \\
\text { training with Lokomat }\end{array}$ & $\begin{array}{l}8 \text { users could walk without assistance and the } 15.3 \% \text { of the rest } \\
\text { of the patients had an improvement in their gait pattern. }\end{array}$ \\
\hline \multirow{4}{*}{ GT1 RehaStim [37] } & \multirow{4}{*}{18} & $\begin{array}{l}-30 \mathrm{~min} \text { of robot training }+10 \mathrm{~min} \text { of } \\
\text { stretching exercises }\end{array}$ & \multirow{4}{*}{$\begin{array}{l}\text { The results were satisfactory in all the experiments and } \\
\text { maintained } 1 \text { month after the treatment had finished. }\end{array}$} \\
\hline & & - 10 min walk test & \\
\hline & & -6 min walk test & \\
\hline & & - Hip kinematics, speed and step length & \\
\hline
\end{tabular}

Table 2 Devices for CP and upper limbs

\begin{tabular}{|c|c|c|c|}
\hline Device & $\begin{array}{l}\text { Number of } \\
\text { patients }\end{array}$ & Therapies and measurements & Results \\
\hline InMotion2 [39] & 12 & Robotic therapy twice a week for 8 weeks & $\begin{array}{l}\text { Improvements in total QUEST and Fugl-Meyer Assessment } \\
\text { Scores }\end{array}$ \\
\hline InMotion 3 & - & - & Hasn't found any experiments with CP published in literature. \\
\hline Hapic-Master [11] & 9 & $\begin{array}{l}\text { Composite of } 3 \text { timed upper extremity tasks and } \\
\text { several measurements of reaching kinematics }\end{array}$ & Improved in measures of motor activity in the MA \\
\hline Armeo & - & - & Hasn't found any experiments with CP published in literature. \\
\hline \multirow[b]{2}{*}{ YouGrabber [44] } & \multirow[b]{2}{*}{5} & 9 sessions of $45 \mathrm{~min}$ each one & \multirow[b]{2}{*}{$\begin{array}{l}\text { Four of five patients showed improvements in all assessments } \\
\text { (MA) }\end{array}$} \\
\hline & & $\begin{array}{l}\text { The task carried out involved hand grasping and } \\
\text { releasing, wrist pronation and supination and } \\
\text { arm reaching }\end{array}$ & \\
\hline \multirow[t]{2}{*}{ REAPlan [45] } & \multirow[t]{2}{*}{16} & \multirow[t]{2}{*}{$\begin{array}{l}\text { In robotic group, } 8 \text { users conducting } 3 \\
\text { conventional therapy sessions and } 2 \text { robotic- } \\
\text { assisted sessions per week over } 8 \text { weeks }\end{array}$} & $\begin{array}{l}\text { Measures such as QUEST and PEDI were analyzed. There is } \\
\text { evidence that robotic therapy is effective since outcome } \\
\text { measures improved significantly more in the robotic group than } \\
\text { in the control group. }\end{array}$ \\
\hline & & & Long term effects of the therapy \\
\hline
\end{tabular}

There is widespread interest in using VR in the rehabilitation of children with CP to address upper $[50,51]$ and lower extremity motor functions [52]. Yoo and colleagues [50] investigated the effectiveness of a combined EMG biofeedback and VR intervention system to improve muscle imbalance between the triceps and biceps during reaching movements in three children with spastic $\mathrm{CP}$; they reported improved muscle imbalance ratios between the triceps and biceps, compared to traditional EMG-based biofeedback training. Another case report [53] investigated the effects of VR therapy on cortical reorganization and associated motor function in an 8-year-old child with hemiparetic CP. After VR therapy, the altered activations disappeared and the contralateral primary sensorimotor cortex was activated. This neuroplastic change was associated with enhanced functional motor skills that were not possible before the intervention. The results show 
that the use of biofeedback and VR-based biofeedback in the rehabilitation of children with $\mathrm{CP}$ is a highly promising area, and further research is encouraged.

\section{Translation from research to clinical scenarios}

Few articles describe how to translate these research studies into clinical practice; however, this is a key issue related to the effectiveness of a new rehabilitation tool. This section describes some of these studies. The research concepts of some robotic devices for the rehabilitation of CP and stroke were translated to clinical practice.

Sukal-Moulton et al. [52] evaluated the effectiveness of a portable robotic device for robot-based ankle rehabilitation for children with CP. The study reveals that the outcome measures collected in the clinical treatment are similar to those of previous research. The participants were children with GMFCS I, II, or III, seen twice a week for 75-minute sessions for a total of 6 weeks. The improvements were significant in all main outcome measures except for the GMFM.

The use of robotic systems in the clinic may provide better controlled movements than manual exercises, and the numerous repetitions of practicing a movement, which is allowed by robotic devices, is an important advantage of this type of training. Moreover, the video games with goal-directed training as part of the therapy motivate children to participate in the clinic and improve motor learning.

Lo et al. [54] presented an interesting long-term study about the use of robot-assisted therapy for the rehabilitation of patients with long-term deficits after stroke. No statistical differences were reported when robot-assisted therapy was compared to intensive physical therapy programs. The clinical question beyond this paper was related to how intensive programs could be carried out at a lower cost; maybe robotassisted therapy is the answer.

The combination of VR with robotic training offers improvements in gait function [55] and muscle power generation during gait. The combination of motivational environments with passive-as-required robotic training could be related to the role of motor imaginary, observation, and motivation on learning and the neuroplasticity of the human brain [56,57]. Mirallas [58] indicated that, especially in the upper limbs, the higher activity provided by robotic devices helps provide better rehabilitation, and the results are maintained in the long term. Another study [52] demonstrated that treatment effects in the protocol applied in the clinic had statistically equivalent results to those seen in the research laboratory.

Nevertheless, the cost effectiveness of robotic devices is still a real problem for rehabilitation if we compare with traditional therapies [59]. Moreover, there is bibliography that does not demonstrate advantages of using locomotor training instead of physical therapy [60].

\section{Conclusions}

Robot-based therapies for children with CP are receiving more attention from the scientific community. This review has presented the state of the art of robot-assisted rehabilitation for people with $\mathrm{CP}$ and the most relevant devices to carry out these treatments, both for the upper and lower limbs.

Robotic therapies for the rehabilitation in children with $\mathrm{CP}$ allow physical and cognitive integration, and this combination is expected to lead to better treatment results. In this context, the design of virtual scenarios in combination with robotic devices provides promising results, although some authors recommend that VR be used only as a complement to other common therapies, not as a replacement [61].

In the same way, the combination between passive stretching and active movement using a portable robot has demonstrated improvements in joint biomechanical properties, motor control performance, and functional capability in balance and mobility for children with CP [62]. Nevertheless, no platforms evaluated this concept in a meaningful clinical trial.

Rehabilitation programs based on robotics adapted to the special needs of an individual user are expensive and therefore limited resources hinder the achievement of optimal therapy [8]. Moreover, specialized technicians are needed to control the robotic technology, and this means higher costs to the family and society.

\section{Conflict of Interest}

The authors declare no competing financial interests.

\section{Acknowledgements}

We have to acknowledge the Spanish Ministry of Economy and Competitiveness.

\section{Funding}

Project CPWaker, under contract DPI2012-39133-C03-01 "CPWalker-Robotic Platform for Gait Rehabilitation and Training in patients with Cerebral Palsy".

\section{References}

Bax M, Goldstein M, Rosenbaum P, Leviton A, Paneth N, et al. (2005) Proposed definition and classification of cerebral palsy, April 2005. Dev Med Child Neurol 47: 571-576.

Novak I (2014) Evidence-based diagnosis, health care, and rehabilitation for children with cerebral palsy. J Child Neurol 29: 1141-1156.

Confederación Española de Federaciones y Asociaciones de Atención a Personas con Parálisis Cerebral y Afines A (2014) Tipos de Parálisis cerebral-Confederación Aspace. Asp Web Page n.d. http://www.aspace.org/paralisis-cerebral/tipos-deparalisis-cerebral. 
Palisano R, Rosenbaum P, Walter S, Russell D, Wood E, et al. (1997) Development and reliability of a system to classify gross motor function in children with cerebral palsy. Dev Med Child Neurol 39: 214-223.

Harvey A, Graham HK, Morris ME, Baker R, Wolfe R (2007) The Functional Mobility Scale: ability to detect change following single event multilevel surgery. Dev Med Child Neurol 49: 603-607.

Bower E (1997) The multiply handicapped child. In: Wilson BA, McLellan LD, editors. Rehabil. Stud. Handb., Cambridge University Press p.315-354.

Ketelaar $M$, Vermeer A, Hart $H$, van Petegem-van Beek $E$, Helders PJ (2001) Effects of a functional therapy program on motor abilities of children with cerebral palsy. Phys Ther 81 : 1534-1545.

Meyer-Heim A, van Hedel HJ a (2013) Robot-assisted and computer-enhanced therapies for children with cerebral palsy: current state and clinical implementation. Semin Pediatr Neurol 20:139-145.

Shonkoff J, Meisels S (2000) Handbook of Early Childhood Intervention. second edn. Cambridge University Press.

10. Winter S, Autry A, Boyle C, Yeargin-Allsopp M (2002) Trends in the prevalence of cerebral palsy in a population-based study. Pediatrics 110: 1220-1225.

11. Jones MA, McEwen IR, Hansen L (2003) Use of power mobility for a young child with spinal muscular atrophy. Phys Ther 83 253-262.

12. Johnson A (2002) Prevalence and characteristics of children with cerebral palsy in Europe. Dev Med Child Neurol 44: 633-640.

13. Centers for Disease Control and Prevention (CDC) (2004) Economic costs associated with mental retardation, cerebral palsy, hearing loss, and vision impairment--United States, 2003. MMWR Morb Mortal Wkly Rep 53: 57-59.

14. McGinley JL, Dobson F, Ganeshalingam R, Shore BJ, Rutz E, et al. (2012) Single-event multilevel surgery for children with cerebral palsy: a systematic review. Dev Med Child Neurol 54: 117-128.

15. Krebs HI, Ladenheim B, Hippolyte C, Monterroso L, Mast J (2009) Robot-assisted task-specific training in cerebral palsy. Dev Med Child Neurol 51 Suppl 4: 140-145.

16. Parkes J, Caravale B, Marcelli M, Franco F, Colver A (2011) Parenting stress and children with cerebral palsy: a European cross-sectional survey. Dev Med Child Neurol 53: 815-821.

17. Meyer-Heim A, Ammann-Reiffer C, Schmartz A, Schäfer J, Sennhauser $\mathrm{FH}$, et al. (2009) Improvement of walking abilities after robotic-assisted locomotion training in children with cerebral palsy. Arch Dis Child 94: 615-620.

18. Dollar AM, Herr H (2007) Active Orthoses for the Lower-Limbs: Challenges and State of the Art. 2007 IEEE 10th Int. Conf. Rehabil. Robot., IEEE 968-977.

19. Kangude A, Burgstahler B, Kakastys J, Durfee W (2009) Single channel hybrid FES gait system using an energy storing orthosis: preliminary design. Conf Proc IEEE Eng Med Biol Soc 2009: 6798-6801.

20. Gharooni $\mathrm{MOH}$, Tokhi S (2000) The use of elastic element in a hybrid orthosis for swing phase generation in orthotic gait. 5 Annu. Conf Int. Funct. Electr. Stimul. Soc.
Farris RJ, Quintero HA, Withrow TJ, Goldfarb M (2009) Design and simulation of a joint-coupled orthosis for regulating fesaided gait in robotics and automation. IEEE Int. Conf. 1916-1922.

Durfee WK, Goldfarb M (1992) Design of a controlled-brake orthosis for regulating fes-aided gait. Annu. Int. Conf. IEE DOI 1337-1338.

Popovic D, Tomovic R, Schwirtlich L (1989) Hybrid assistive system--the motor neuroprosthesis. IEEE Trans Biomed Eng 36: 729-737.

Obinata G, Fukada S, Matsunaga T, Iwami T, Shimada Y, et al. (2007) Hybrid control of powered orthosis and functional neuromuscular stimulation for restoring gait. Conf Proc IEEE Eng Med Biol Soc 2007: 4879-4882.

Al-Khodairy P, Brodard A, Fournier R, Bouri J, Clavel M, et al. (2004) A study of a knee extension controlled by a closed loop functional electrical stimulation. Annu. Conf. Int. Funct. Electr. Stimul. Soc 2004.

Stauffer Y, Allemand Y, Bouri M, Fournier J, Clavel R, et al. (2009) The WalkTrainer--a new generation of walking reeducation device combining orthoses and muscle stimulation. IEEE Trans Neural Syst Rehabil Eng 17: 38-45.

Krebs HI, Hogan N, Aisen ML, Volpe BT (1998) Robot-aided neurorehabilitation. IEEE Trans Rehabil Eng 6: 75-87.

Made for Movement (2014) NF-Walker | Made for Movement n.d. http://madeformovement.com/products/nf-walker.

Smania N, Gandolfi M, Marconi V, Calanca A, Geroin C, et al. (2012) Applicability of a new robotic walking aid in a patient with cerebral palsy. Case report. Eur J Phys Rehabil Med 48: 147-153.

Made for Movement web page | Outer movement (2015) Inner strength. n.d. http://madeformovement.com/.

Made for Movement (2014) Innowalk | Made for Movement n.d. http://madeformovement.com/products/innowalk\#top.

Made for Movement (2014) Innowalk Pro | Made for Movement n.d. http://madeformovement.com/products/innowalk-pro.

Johansson AK, Nohlert E, Johansson A, Norring C, Tegelberg A (2009) Dentists and eating disorders--knowledge, attitudes, management and experience. Swed Dent J 33: 1-9.

Meyer A, Kofler M, Quirbach E, Matzak H, Fröhlich K, et al. (2007) Prospective, blinded, randomized crossover study of gait rehabilitation in stroke patients using the Lokomat gait orthosis. Neurorehabil Neural Repair 21: 307-314.

Verazaluce-Rodríguez PR, Rodríguez-Martínez P, Neri-Gámez S, Hernández-Aquino RM (2014) Evolución de la marcha en pacientes con parálisis cerebral y desplazamiento asistido, mediante su entrenamiento con equipo de asistencia robótica. Rehabilitación 48: 3-8.

Borggraefe I, Kiwull L, Schaefer JS, Koerte I, Blaschek A, et al. (2010) Sustainability of motor performance after roboticassisted treadmill therapy in children: an open, non-randomized baseline-treatment study. Eur J Phys Rehabil Med 46: 125-131.

Smania N, Bonetti P, Gandolfi M, Cosentino A, Waldner A, et al. (2011) Improved gait after repetitive locomotor training in children with cerebral palsy. Am J Phys Med Rehabil 90: 137-149.

Frizera A, Raya R, Pons JL, Abellanas A, Ceres R (2008) The smart walkers as geriatric assistive device. 6th Int. Conf. Int. Soc. Gerontechnology. 
39. Fasoli SE, Fragala-Pinkham M, Hughes $\mathrm{R}$, Hogan $\mathrm{N}$, Krebs $\mathrm{HI}$, et al. (2008) Upper limb robotic therapy for children with hemiplegia. Am J Phys Med Rehabil 87: 929-936.

40. Waldner A (2008) Robot Assisted Therapy in neurorehabilitation. Eura Medicophys 44: 1-3.

41. Qiu Q, Ramirez DA, Saleh S, Fluet GG, Parikh HD, et al. (2009) The New Jersey Institute of Technology Robot-Assisted Virtual Rehabilitation (NJIT-RAVR) system for children with cerebral palsy: a feasibility study. J Neuroeng Rehabil 6: 40.

42. Sanchez RJ, Liu J, Raos (2006) Automating arm movement training following severe stroke: Functional exercises with quantitative feedback in a gravity reduced environment. IEEE Trans Neural Syst Rehabil 14: 378-389.

43. YouRehab Company (2014) Rehabilitación de YouGrabber para los miembros superiores - YouRehab - News y comunicados de prensa n.d. http://news.medicalexpo.es/press/yourehab/ rehabilitacion-yougrabber-miembrossuperiores-81152-162557.html.

44. YouRehab Company (2014) YouRehab (YouGrabber) n.d. http:// yourehab.com/yougrabber/clinical-studies/padiatrics/.

45. Gilliaux M, Renders A, Dispa D, Holvoet D, Sapin J, et al. (2015) Upper limb robot-assisted therapy in cerebral palsy: a singleblind randomized controlled trial. Neurorehabil Neural Repair 29: 183-192. doi:10.1177/1545968314541172.

46. Fasoli SE, Ladenheim B, Mast J, Krebs HI (2012) New horizons for robot-assisted therapy in pediatrics. Am J Phys Med Rehabil 91 S280-289.

47. Newport R (2006) Ventajas de la rehabilitación asistida mediante robot en la recuperación de las funciones motriz y visuoespacial en pacientes en fase de recuperación de un accidente cerebrovascular. RevEsp Geriatría Y Gerontol 41: 66-73.

48. Castelli E (2011) Robotic movement therapy in cerebral palsy. Dev Med Child Neurol 53: 481.

49. Leiper Cl, Miller A, Lang J, Herman R (1981) Sensory feedback for head control in cerebral palsy. Phys Ther 61: 512-518.

50. Yoo JW, Lee DR, Sim YJ, You JH, Kim CJ (2014) Effects of innovative virtual reality game and EMG biofeedback on neuromotor control in cerebral palsy. Biomed Mater Eng 24: 3613-3618.

Fluet GG, Qiu Q, Kelly D, Parikh HD, Ramirez D, et al. (2010) Interfacing a haptic robotic system with complex virtual environments to treat impaired upper extremity motor function in children with cerebral palsy. Dev Neurorehabil 13: 335-345.

52. Sukal-Moulton T, Clancy T, Zhang L-Q, Gaebler-Spira D (2014) Clinical application of a robotic ankle training program for cerebral palsy compared to the research laboratory application: does it translate to practice? Phys Med Rehabil 95: 1433-1440.

You SH, Jang SH, Kim YH, Kwon YH, Barrow I, et al. (2005) Cortical reorganization induced by virtual reality therapy in a child with hemiparetic cerebral palsy. Dev Med Child Neurol 47: 628-635.

54. Lo AC, Guarino PD, Richards LG, Haselkorn JK, Wittenberg GF, et al. (2010) Robot-assisted therapy for long-term upper-limb impairment after stroke. N Engl J Med 362: 1772-1783.

55. Mirelman A, Patritti BL, Bonato P, Deutsch JE (2010) Effects of virtual reality training on gait biomechanics of individuals poststroke. Gait Posture 31: 433-437.

56. Morgan C, Novak I, Badawi N (2013) Enriched environments and motor outcomes in cerebral palsy: systematic review and metaanalysis. Pediatrics 132: e735-746.

57. Kelly C, Foxe JJ, Garavan H (2006) Patterns of normal human brain plasticity after practice and their implications for neurorehabilitation. Arch Phys Med Rehabil 87: S20-29.

58. Mirallas Martínez JA (2004) Evidencia científica de los progresos en la rehabilitación de la enfermedad cerebrovascular. Rehabilitación 38: 246-249.

59. Teng P, Bateman NW, Darcy KM, Hamilton CA, Maxwell GL, et al. (2011) An economic analysis of robot-assisted therapy for longterm upper-limb impairment after stroke. Stroke 42: 2630-2632.

60. Duncan PW, Sullivan KJ, Behrman AL, Azen SP, Wu SS, et al. (2011) Body-weight-supported treadmill rehabilitation after stroke. N Engl J Med 364: 2026-2036.

61. Jelsma J, Pronk M, Ferguson G, Jelsma-Smit D (2013) The effect of the Nintendo Wii Fit on balance control and gross motor function of children with spastic hemiplegic cerebral palsy. Dev Neurorehabil 16: 27-37.

Wu YN, Hwang M, Ren Y, Gaebler-Spira D, Zhang LQ (2011) Combined passive stretching and active movement rehabilitation of lower-limb impairments in children with cerebral palsy using a portable robot. Neurorehabil Neural Repair 25: 378-385. 